\title{
The Disruptive Effect of Cocaine on Prepulse Inhibition Is Prevented by Repeated Administration in Rats
}

\author{
John J. Byrnes, Ph.D., and Ronald P. Hammer, Jr., Ph.D.
}

These experiments tested the hypothesis that pretreatment with a behaviorally sensitizing regimen of cocaine alters the ability of cocaine to disrupt prepulse inhibition (PPI). Male Sprague-Dawley rats were treated with cocaine $(30 \mathrm{mg} / \mathrm{kg}$, i.p.) or saline vehicle for seven consecutive days followed by challenge treatment seven days later. Repeated cocaine treatment produced sensitization of stereotyped activity. Cocaine challenge following repeated vehicle treatment significantly reduced PPI, but this effect was completely abolished by repeated cocaine treatment. These data suggest that neuroadaptation following repeated treatment might prevent PPI disruption caused by psychomotor stimulants. [Neuropsychopharmacology 22:551-554, 2000] (C) 2000 American College of Neuropsychopharmacology. Published by Elsevier Science Inc.
KEY WORDS: Behavioral sensitization; Cocaine; Prepulse Inhibition; Schizophrenia; Sensorimotor gating

In humans, repeated exposure to psychostimulants such as amphetamine or cocaine increases sensitivity to these drugs which may precipitate psychosis (Ellison 1994). Behavioral sensitization to psychostimulants can also be elicited in experimental animals, and is associated with increased dopamine neurotransmission in the nucleus accumbens (Kalivas and Stewart 1991). Thus, psychostimulant sensitization in rodents is widely used to model neuroadaptive changes underlying schizophrenia (Kalivas and Stewart 1991; Robinson and Becker 1986).

Disruption of prepulse inhibition (PPI) is believed to reflect sensorimotor gating deficits present in patients with schizophrenia (Swerdlow et al. 1994). PPI is the attenuation of startle response to a high intensity stimu-

From the Departments of Pharmacology and Experimental Therapeutics, and Psychiatry, Tufts University School of Medicine/New England Medical Center, Boston, MA.

Address correspondence to: Ronald P. Hammer, Jr., Ph.D., Department of Psychiatry, Box 1007, New England Medical Center, 750 Washington Street, Boston, MA 02111.

Received June 17, 1999; revised November 16, 1999; accepted November 20, 1999. lus (e.g., auditory) following exposure to a low intensity prestimulus. Psychostimulants elicit PPI deficits in experimental animals presumably via indirect dopamine receptor stimulation in the nucleus accumbens, providing another experimental model of schizophrenia symptoms (Swerdlow et al. 1992, 1994).

As models of schizophrenia, these paradigms might be expected to exhibit a certain degree of consistency reflected by enhanced PPI disruption in behaviorally sensitized animals. However, attempts to determine whether amphetamine- or apomorphine-induced PPI deficits are augmented by repeated treatment have yielded conflicting results (Druhan et al. 1998; Mansbach et al. 1988; Taylor et al. 1995; Zhang et al. 1998). Thus, the present study was conducted to determine whether these models could be differentiated when cocaine was used as the sensitizing agent.

\section{MATERIALS AND METHODS}

\section{Animals}

Male Sprague-Dawley rats (National Cancer Institute, Frederick, MD) weighing 200-250 g were housed in 
groups of $2-3$ on a 12:12 hr light:dark cycle with food and water available ad libitum. All procedures were reviewed and approved by the Tufts-New England Medical Center Animal Care and Use Committee, and were conducted in accordance with the Guide for the Care and Use of Laboratory Animals as adopted and promulgated by the National Institutes of Health.

\section{Behavioral Assessment}

The procedure for monitoring stereotypy has been described in detail elsewhere (Byrnes et al. 2000). Briefly, animals were placed individually into testing chambers $(45 \times 24 \times 15 \mathrm{~cm})$ and the percent time spent engaging in stereotypic movement was quantified using the PolyTrack Video Tracking System (San Diego Instruments, San Diego, CA). The tracking parameters used accurately reflect small movements including normal grooming and psychostimulant-induced stereotypy (Robinson and Becker 1986).

Assessment of startle response and PPI was accomplished using an SR-Pilot startle chamber (San Diego Instruments). Stimulus parameters included $65 \mathrm{~dB}$ broad band background noise and two trial types: a basic startle pulse stimulus of $40 \mathrm{~ms}, 115 \mathrm{~dB}$ broad band noise, and a prepulse sequence consisting of a $40 \mathrm{~ms}, 85$ $\mathrm{dB}$ stimulus preceding the startle stimulus by $100 \mathrm{~ms}$. Peak startle amplitude was determined in arbitrary re-

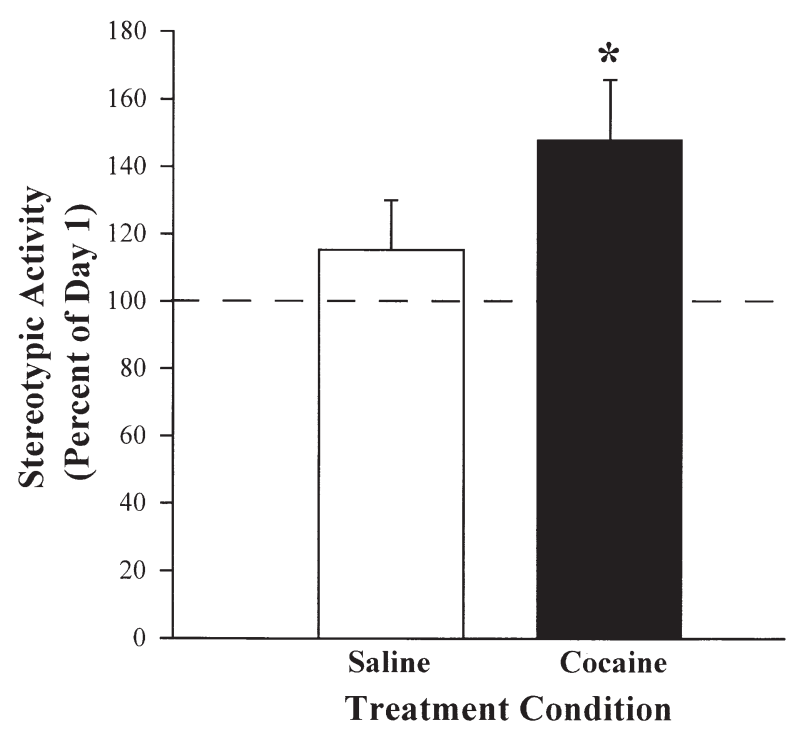

Figure 1. Stereotypic activity is augmented following repeated cocaine treatment. Data (mean \pm SEM for individual animals) are normalized to represent activity expressed following Day 14 challenge as a percent of that on Day 1 . Paired t-test for Day 1 vs. Day 14: Repeated Saline $[t(6)=$ 0.87, $p<.42]$; Repeated Cocaine $[t(13)=3.58, p<.004]$. sponse units. Each animal received 63 stimuli in pseudorandom order with $15 \mathrm{~s}$ interstimulus intervals. Percent of PPI expressed by individual animals within each test session was calculated as follows:

\section{$100-[($ mean Prepulse response/ mean Pulse response $) \times 100$ ]}

\section{Experimental Design}

Effect of Repeated Cocaine on Stereotypic Behavior. Animals received either cocaine $(30 \mathrm{mg} / \mathrm{kg}$, i.p.; NIDA Drug Supply Program) or vehicle $(0.9 \%$ saline, $1 \mathrm{ml} / \mathrm{kg}$, i.p.) once daily for a total of seven days (Days 1-7). Each animal, then, received the same treatment following a seven day withdrawal period (Day 14). The magnitude of stereotypic activity was assessed for $50 \mathrm{~min}$ following treatment on Days 1 and 14. This paradigm significantly augments motor behavior in the absence of any apparent seizure activity (Byrnes et al. 1999; Pierce et al. 1996).

Effect of Repeated Cocaine on PPI and Startle. Two days prior to treatment, experimental groups were matched to ensure uniform pretreatment startle responding. All treatment procedures were identical to those described for Experiment 1, except that animals were challenged on Day 14 with either cocaine ( $30 \mathrm{mg} / \mathrm{kg}$, i.p.) or saline followed $5 \mathrm{~min}$ later by PPI and startle testing.

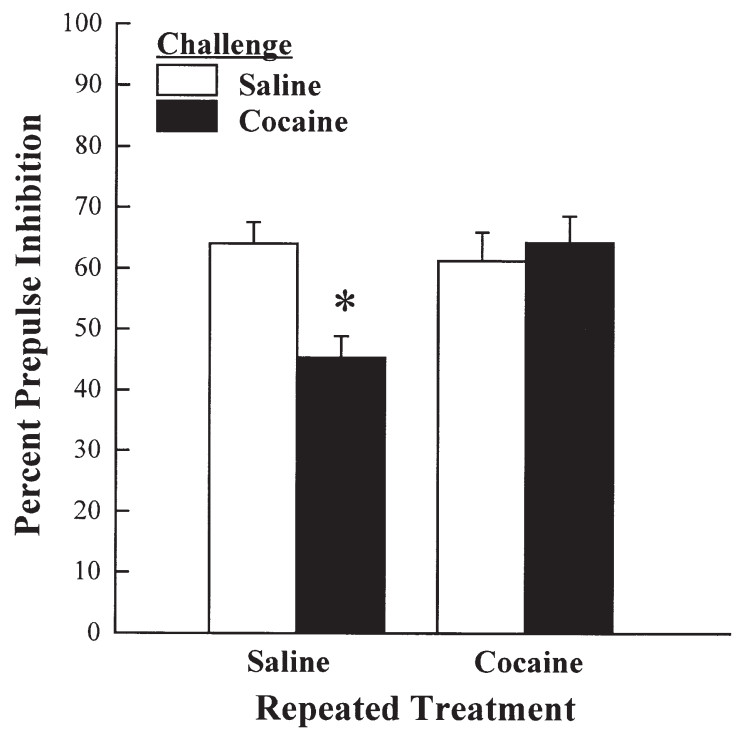

Figure 2. Cocaine-induced disruption of PPI is blocked by repeated treatment. Data (mean \pm SEM) represent percent PPI upon Day 14 challenge. Two-way ANOVA: Repeated Treatment $[F(1,30)=3.98, p<.05]$; Challenge Treatment $[\mathrm{F}(1,30)=3.72, p<.064]$, Interaction $[\mathrm{F}(1,30)=7.38, p<.01]$. * significant $(p<.05)$ difference compared to all other treatment groups using Student Neuman-Keuls. 
Table 1. Effect of Repeated Treatment on Startle Amplitude

\begin{tabular}{llccc}
\hline $\begin{array}{c}\text { Chronic Treatment } \\
\text { Days 1-7 }\end{array}$ & \multicolumn{1}{c}{$\begin{array}{c}\text { Drug Challenge } \\
\text { Day } \mathbf{~ 1 4}\end{array}$} & $\boldsymbol{n}$ & Pulse Amplitude & Prepulse Amplitude \\
\hline Saline & Saline & 10 & $296 \pm 86$ & $121 \pm 51$ \\
Saline & Cocaine $(30 \mathrm{mg} / \mathrm{kg})$ & 7 & $249 \pm 45$ & $135 \pm 27$ \\
Cocaine $(30 \mathrm{mg} / \mathrm{kg})$ & Saline & 7 & $432 \pm 80$ & $167 \pm 37$ \\
Cocaine $(30 \mathrm{mg} / \mathrm{kg})$ & Cocaine $(30 \mathrm{mg} / \mathrm{kg})$ & 7 & $437 \pm 94$ & $154 \pm 35$ \\
\hline
\end{tabular}

Data represent mean startle responses $( \pm$ SEM) to Pulse and Prepulse stimuli following Day 14 drug challenge. Two-way ANOVA statistics: Repeated Treatment [Pulse, F(1,29) $=3.78, p<.062$; Prepulse, F $(1,30)=0.58, p<.45]$, Challenge Treatment $[$ Pulse, $\mathrm{F}(1,29)=0.04, p<.83 ;$ Prepulse, $\mathrm{F}(1,30)=0.000, p<.98]$ Interaction [Pulse, $\mathrm{F}(1,29)=0.07, p<.79$; Prepulse, $\mathrm{F}(1,30)=0.095, p<.76]$.

\section{RESULTS AND DISCUSSION}

Cocaine challenge significantly increased stereotypic activity following repeated treatment (Figure 1); group mean percent activity was $55.3 \pm 5.0 \%$ after cocaine challenge on Day 1 and $73.3 \pm 7.1 \%$ on Day 14 . In addition, the incidence of abnormal focused behaviors (e.g., intense sniffing, repetitive head bobbing) was greater after cocaine treatment on Day 14 than on Day 1. Repeated saline treatment produced equivalent amounts of small movements and grooming at both test times; group mean percent activity was $63.6 \pm 4.4 \%$ on Day 1 and $71.3 \pm 7.1 \%$ on Day 14 .

Exposure to a sensitizing regimen of cocaine also altered the drug's ability to disrupt PPI (Figure 2). Cocaine challenge on Day 14 in animals treated repeatedly with saline disrupted PPI with a magnitude similar to that reported elsewhere (Martinez et al. 1999). However, repeated cocaine treatment produced a complete blockade of this effect without altering PPI response to saline challenge. This is consistent with the effect of repeated amphetamine treatment which produces locomotor sensitization but not augmentation of PPI deficits (Druhan et al. 1998). Repeated cocaine treatment also produced a nonsignificant rise $(61 \%)$ in startle response to Pulse stimuli following challenge with either cocaine or saline (Table 1), an effect which might reflect withdrawal-induced anxiety (Sarnyai 1998; Mutschler and Miczek 1998). Since this effect was characterized by proportional changes in Pulse- and Prepulse-induced responses, it is unlikely that increased startle amplitude biased the magnitude of PPI observed.

The opposing effects of repeated cocaine treatment on motor behavior and PPI might be explained by differential adaptation of dopamine receptors. Behavioral sensitization to cocaine is associated with enhanced $D_{1}$ like receptor sensitivity in the nucleus accumbens (Henry and White 1991). Conversely, repeated treatment with selective $D_{2}$-like receptor agonists appears to downregulate $\mathrm{D}_{2}$-like receptor density (Subramaniam et al. 1992), reduce the level of $D_{2}$-like receptor-coupled $G_{i}$ protein (Nestler et al. 1990), and decrease the physio- logical response to $D_{2}$-like agonists (Henry et al. 1998) in the nucleus accumbens. Thus, cocaine-induced $\mathrm{D}_{1}$ like receptor enhancement with concurrent desensitization of $\mathrm{D}_{2}$-like receptors could account for the simultaneous sensitization of motor activity and tolerance to PPI disruption. Accordingly, the present finding is of particular interest with regard to the therapeutic potential of subchronic treatment with selective dopamine receptor agonists in schizophrenia.

\section{ACKNOWLEDGMENTS}

This work was supported by USPHS Awards DA09822 (RPH) and MH19924 (JJB). The authors wish to thank Horacio Daubon and Dwight Dishmon, who were supported by HL07785, for expert assistance, and Dr. S. Barak Caine for his helpful consultation.

\section{REFERENCES}

Byrnes JJ, Pantke MM, Onton J, Hammer RP (2000): Chronic inhibition of nitric oxide synthase in the ventral tegmental area attenuates cocaine-mediated motor behavior in rats. Prog Neuro Psychopharmacol Biol Psychiatry (In Press)

Druhan JP, Geyer MA, Valentino RJ (1998): Lack of sensitization to the effects of d-amphetamine and apomorphine on sensorimotor gating in rats. Psychopharmacology 135:296-304

Ellison G (1994): Stimulant-induced psychosis, the dopamine theory of schizophrenia, and the habenula. Brain Res Rev 19:223-239

Henry DJ, Hu XT, White FJ (1998): Adaptations in the mesoaccumbens dopamine system resulting from repeated administration of dopamine $D_{1}$ and $D_{2}$ receptor-selective agonists: Relevance to cocaine sensitization. Psychopharmacology 140:233-242

Henry DJ, White FJ (1991): Repeated cocaine administration causes persistent enhancement of $D_{1}$ dopamine receptor sensitivity within the rat nucleus accumbens. J Pharmacol Exp Ther 258:882-890

Kalivas PW, Stewart J (1991): Dopamine transmission in the 
initiation and expression of drug- and stress-induced sensitization of motor activity. Brain Res Rev 16:223244

Mansbach RS, Geyer MA, Braff DL (1988): Dopaminergic stimulation disrupts sensorimotor gating in the rat. Psychopharmacology 94:507-514

Martinez ZA, Ellison GD, Geyer MA, Swerdlow NR (1999): Effects of sustained cocaine on sensorimotor gating of startle in rats. Psychopharmacology 142:253-260

Mutschler NH, Miczek KA (1998): Withdrawal from i.v. cocaine "binges" in rats: Ultrasonic distress calls and startle. Psychopharmacology 135:161-168

Nestler EJ, Terwilliger RZ, Walker JR, Sevarino KA, Duman RS (1990): Chronic cocaine treatment decreases levels of the $G$ protein subunits $G_{i}$ and $G_{0}$ in discrete regions of rat brain. J Neurochem 157:53-56

Pierce RC, Bell K, Duffy P, Kalivas PW (1996): Repeated cocaine augments excitatory amino acid transmission in the nucleus accumbens only in rats having developed behavioral sensitization. J Neurosci 16:1550-1560

Robinson TE, Becker JB (1986): Enduring changes in brain and behavior produced by chronic amphetamine administration: A review and evaluation of animal models of amphetamine psychosis. Brain Res Rev 11:157-198

Sarnyai Z (1998): Neurobiology of stress and cocaine addiction. Studies on corticotropin-releasing factor in rats, monkeys, and humans. Ann NY Acad Sci 851:371-387

Subramaniam S, Lucki I, McGonigle P (1992): Effects of chronic treatment with selective agonists on the subtypes of dopamine receptors. Brain Res 571:313-322

Swerdlow NR, Braff DL, Taaid N, Geyer MA (1994): Assessing the validity of an animal model of deficient sensorimotor gating in schizophrenic patients. Arch Gen Psychiatry 51:139-154

Swerdlow NR, Caine SB, Geyer, MA (1992): Regionally selective effects of intracerebral dopamine infusion on sensory gating of the startle reflex in rats. Psychopharmacology 108:189-195

Taylor MK, Ison JR, Schwarzkopf SB (1995): Effects of single and repeated exposure to apomorphine on the acoustic startle reflex and its inhibition by a visual prepulse. Psychopharmacology 120:117-127

Zhang J, Engel JA, Soderpalm B, Svensson L (1998): Repeated administration of amphetamine induces sensitization to its disruptive effect on prepulse inhibition in the rat. Psychopharmacology 135:401-406 